NBER WORKING PAPER SERIES

INTERNATIONAL DIFFERENCES IN SOCIAL SECURITY AND SAVING

Martin Feldstein

Working Paper No. $\underline{355}$

NATIONAL BUREAU OF ECONOMIC RESEARCH 1050 Massachusetts Avenue

Cambridge MA 02138

May 1979 


\title{
INTERNATIONAL DIFFERENCES IN SOCIAL SECURITY AND SAVING
}

\author{
Martin Feldstein
}

\section{SUMMARY}

The U.S. Social Security Administration, in cooperation with similar agencies in other countries, recently developed estimates of social security benefits for twelve major industrial countries. More specifically, these estimates provide information on the ratio of social security pension to preretirement earnings for a new1y retired couple in which the man had the average earnings in manufacturing industry.

The present paper uses these new data to estimate the effects of social security benefits on saving and retirement in an extended life cycle model. The parameter estimates indicate that, with retirement behavior given, social security significantly reduces private saving; an increase of the benefit-to-earnings ratio by 10 percentage points reduces the saving rate by approximately 3 percentage points. The reduced form parameter indicates that allowing for the effect on saving of induced retirement lowers this implied decrease in saving from 3 percentage points to about 2 percentage points.

\author{
Martin Feldstein \\ National Bureau of Economic Research \\ 1050 Massachusetts Avenue \\ Cambridge, Massachusetts 02138
}

(617) 868-3905 
International Differences in Social Security and Saving

Martin Feldstein*

The traditional life cycle theory of saving implies that an individual who expects to receive social security benefits will reduce his personal saving by a corresponding amount. In a more general theoretical framework, the effect of social security on saving is ambiguous: by inducing changes in retirement behavior or intergenerational transfers, social security can either increase or decrease aggregate private saving. 1 Only empirical analysis can determine the actual net effect of social security.

The retirement benefits that are provided by public social security programs differ significantly among the major industrial countries. These differences provide a potentially useful basis for measuring the impact of social security on aggregate savings. In a previous study (Feldstein, 1977), I estimated the average level of social security benefits for 15 countries and used these estimates to examine how benefits affected aggregate private saving. The results of that study indicate that social security benefits did depress saving by a substantial amount.

\footnotetext{
*Harvard University and the National Bureau of Economic Research. This paper was prepared for presentation at the NBER-SSRC Conference on Empirical Research in Public Economics in Cambridge, England, on June 14-16, 1979. I am grateful to Charles Horioka for his help with this research and to the NBER and National Science Foundation for financial support of this work. This research is part of the NBER Social Insurance Program and of the NBER Program of Capital Formation. The views expressed here are however my own and should not be attributed to any organization.

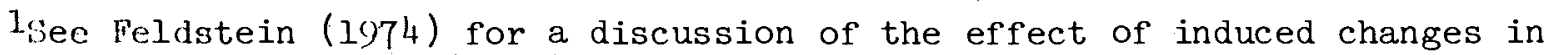
retirement and Barro (1974) for a discussion of intergenerational transfers. Feldstein (1979) discusses other reasons why the implication of the traditional life cycle model may not be appropriate.
} 
A fundamental problem in any study of the effect of social security is estimating the level of benefits that individuals anticipate that they will receive when they retire. In my earlier international study, I used the ratio of the average benefit currently received per retiree to the average per capita income in the country. This "average replacement ratio" is appropriate if the individuals who are working base their estimates of the benefits that they will eventually receive on the experience of those who are currently retired. There are two problems with this approach. The first is conceptual: if the social security program has changed substantially in recent years, the current workers may correctly perceive that the experience of the older individuals who retired many years ago is less relevant than the experience of those who are just retiring. The second is practical: the average level of social security benefits is difficult to calculate in practice for several countries because the data on aggregate benefits do not distinguish retirement benefits from benefits paid to survivors and to the disabled. Dividing total benefits by the number of older persons or the number of retirees produces a value that is very much influenced by the treatment of survivors and the disabled and by their importance relative to retirees. It is frankly surprising that the study based on the "average replacement ratio" permitted parameter estimates that were as plausible, precise and robust as they appeared to be.

The present paper was stimulated by the publication of a new, and I believe more reliable, source of data on social security benefits. The U.S. Social Security Administration, in cooperation with similar agencies in other countries, recently developed estimates of social security benefits for twelve major industrial countries (Haanes-0lsen, 1978). More specifically, the Social Security Administration estimated the ratio of the social security retirement 
pension of a newly retired aged couple to the average earnings of a worker in manufacturing employment. This "new retiree replacement ratio" has the advantage that it is not distorted by the experience of individuals who retired many years ago. Because it is based on a careful analysis of statutory provisions, it is also not subject to the measurement errors in the "average replacement ratio."

Although the "new retiree replacement ratio" should permit more reliable estimates of the effect of social security on saving, this ratio also has significant problems. First, since the benefit schedules are generally progressive and manufacturing workers better paid than average, the Social Security Administration calculation will understate the benefit replacement ratio of the average retiree; the extent of this understatement will differ among countries. Second, no allowance is made for taxes; the effective replacement rate will be understated to the extent that earnings are taxed and social security benefits are not. This discrepancy will also differ among countries, depending on tax rules and on the relative reliance on value added taxes. Third, the "new retiree replacement ratio" contains no information on inflation indexing, a feature that clearly affects the lifetime value of benefits. Finally, we have data only on public retirement pensions. Private pensions have become increasingly important and also differ significantly among countries.l All of these shortcomings can introduce substantial error into the measurement of expected social security benefits.

IThe Social Security Administration study does contain information on private pensions in 5 countries in 1975 that emphasize these differences. For example, while 45 percent of the U.K. working population is covered by private pensions and these average 23 percent of earnings, in the Netherlands 80 percent are covered and benefits average between 7 and 11 percent. 
These problems should be borne in mind in considering the results presented in this paper.

The current study focuses on the estimates based on the "new retiree replacement ratio." "The statistical estimates indicate that savings behavior in the first half of the 1970's in the twelve sample countries is quite consistent with the implications of the extended life cycle model and that higher levels of anticipated benefits do significantly reduce private saving. For comparison, the study also presents estimates based on the "average replacement ratio." Although this variable showed an important effect of social security on saving in the previous study using data for the 1950's, the current study finds no statistically significant effect. It is not clear whether this difference reflects the shift in time, measurement problems in the average replacement ratio, or other factors.l

The next section of this paper reviews the theory and specification of the "extended life cycle model." The data are described in section 2. The estimated parameter values are then presented in section 3. There is a brief concluding section.

\section{The Specification of Saving Behavior}

The net saving in an economy is the difference between the gross saving of the savers and the dissaving of the dissavers. The traditional life cycle model of saving emphasizes that the working population are the savers while the retirees are the dissavers. This implies that the net saving rate will be

IBarro (1979) also studied the experience of the 1950's based on this variable. He used a mix of time series and cross-sections (rather than averaging the data for all sample years) and found a significant social security effect only when he included individual country constant terms. 
higher when the income of the generation of workers is high relative to the income that the retirees had when they were working and saving. A key conclusion of the traditional life cycle model is therefore that an economy with a faster rate of growth of total private income will have a higher private saving rate. 1

The life cycle theory also suggests that an economy's saving rate will be higher when the working age population is large relative to the numbers of retirees and of younger dependents. When the population grows at a constant rate for a long period of time, the demographic composition is also stable and is itself a function of the growth rate. Under these conditions, the effect of the demographic structure might be subsumed in the effect of the growth of total income. A more realistic disequilibrium view of population growth must recognize that the population growth rates have been changing substantially. This in turn implies that the demographic composition of the population should be recognized explicitly in any empirical model of intercountry differences in saving rates.

Previous empirical research by Houthakker $(1961,1965)$ and Modigliani (1970) confirm that the traditional life cycle model is a useful framework for explaining differences in saving rates among countries. In a crosssection of countries, higher saving rates are associated with faster rates of growth of private income and with smaller fractions of the population who are before or beyond the working age.

IThis implication was recognized by Harrod (1948) and later developed and quantified by Modigliani and his collaborators (1954, 1966, 1970). 
This life-cycle model of intercountry differences in saving rates can be extended to include the expected effect of social security benefits. A high level of benefits relative to previous earnings can substitute for private wealth accumulation and should cause individuals to save less for their retirement. This reduces both the gross saving of the working population and the subsequent dissaving of the retirees. In equilibrium, the net saving rate is reduced. The current paper, like Feldstein (1977), therefore adds the social security benefit replacement ratio to the growth and demographic variables of the Houthakker-Modigliani specification.

A weakness of the traditional life cycle model is that it treats the retirement period as fixed. In fact, the fraction of men over age 65 that is working has been falling over time and varies among countries. Men who expect to continue working beyond age 65 will have a smaller incentive to save for retirement. The extended life cycle model with endogenous retirement is developed explicitly in Feldstein $(1974,1977$ ) and will not be repeated here. It suggests that international differences in saving rates depend in a complex way on the labor force participation of older persons, the extent to which benefits are reduced by a "retirement test," the life expectancy of individuals at age 65 , and the ways in which the social security program has changed in recent years. It is clearly impossible to capture all of these effects in an analysis with only 12 country observations. The current study does however explicitly include the labor force participation of the aged in order to test this aspect of the extended life cycle model and to distinguish the direct effects of changes in social security benefits with retirement given from the total changes when retirement can also vary.

The specification of the basic savings function that I have estimated can therefore be written: 
(1)

$$
\frac{S}{Y}=\beta_{0}+\beta_{1} G+\beta_{2} A G E+\beta_{3} D E P+\beta_{4}(B / E)+\beta_{5} \text { LPAGED }
$$

Where $S / Y$ is the private saving rate, $G$ is the growth rate of total private income, $\mathrm{AGE}$ is the ratio of the number of retirees over the age of 65 to the population age 20 to 65 , DEP is the ratio of the number of younger dependents to the working age population, $\mathrm{B} / \mathrm{E}$ is the benefit-earnings replacement ratio, and LPAGED is the labor force participation rate of older men.

Although the extended life cycle theory predicts unambiguously that $\beta_{4}$ is negative, i.e., that higher social security benefits reduce the saving rate when the retirement bahavior is held constant, there are other economists who have asserted that social security may not depress savings. Thus Katona (1965) and Pechman et al. (1968) have argued that individual savers are not rational and that such individuals may ignore social security benefits or may even save more because they perceive that the goal of a more comfortable retirement is brought "within reach" by social security. Barro (1974) also reached the conclusion that social security benefits may not affect aggregate saving (even with fixed retirement rates) because individuals save more in order to increase their bequests to compensate their children for the extra social security taxes that they will bear in the future. The estimate of $\beta_{4}$ provides a direct test of the "irrationality" view of Pechman, et. al as well as of the "offsetting private transfers" view of Barro.l

A complete characterization of the relation between social security and saving requires specifying how the benefit replacement ratio affects the labor force participation rate of older men. A higher benefit replacement

IFor a more general discussion of this "offsetting private tranfers" view, see Feldstein (1979). 
ratio provides a greater incentive to retirel and the lower labor force participation of the aged in turn encourages more saving. The net effect of social security on saving depends on the relative strength of the traditional wealth substitution effect $\left(\beta_{4}\right.$ in equation 1$)$ and the indirect effect of benefits on induced retirement. ${ }^{2}$

of course, the relative strengths of these two effects may differ from time to time and country to country. It is noteworthy that the average rate of labor force participation among older men dropped from 41 percent in my previous study (based on the experience of 1954 to 1960) to only 17 percent in the current sample. 3 Moreover, while the labor force participation of older men ranged between 25 percent and 74 percent in the data for the $1950^{\prime}$ 's, by the $1970^{\prime}$ s the range was reduced to 8 percent to 32 percent; the standard deviation was also more than halved (from 9.6 percentage points to 4.9 percentage points). This suggests both that there is much less information on the effects of the labor force participation in the current sample and that further increases in the social security benefit replacement ratio can no longer have as powerful effect on retirement as they previously did. Intercountry differences in the labor force participation rate of the aged will also reflect a number of other factors, only some of which can be quantified. My previous study, building on earlier work by others, identified the level of income as a significant influence on retirement behavior.

IPrevious international evidence by Aaron (1967), and Feldstein (1977) confirms this effect, as does more detailed microeconomic evidence for the United States (Boskin, 1977 and Pellechio, 1978).

${ }^{2} \mathrm{As}$ well as the irrational effects, induced changes in private intergenerational transfers, etc.

3 The sample of countries is of course slightly different but this accounts for very little of the change. 
Because of offsetting income and substitution effects, a higher level of earnings can either increase or decrease the demand for leisure after age 65. A nonlinear specification indicated that the income effect dominated for the typical country in the sample for the 1950's while the substitution effect dominated for the high income countries in that sample (Feldstein, 1977, pp. 197-98). The same nonlinear specification will be examined in the current study.

The decision to retire should also depend in an important way on whether the payment of social security benefits is contingent on retirement. Unfortunately, there is usually considerable ambiguity about the structure of the retirement test in each country. That ambiguity may explain why a dummy variable representing the retirement test was almost always insignificant in the previous study. A similar variable will nevertheless be included in the current analysis.

The specification of the labor force participation equation is thus:

(2) LPAGED $=\alpha_{0}+\alpha_{1}\left(\frac{\mathrm{B}}{\mathrm{E}}\right)+\alpha_{2}\left(\frac{100}{\mathrm{y}^{*}}\right)+\alpha_{3}\left(\frac{\mathrm{y}^{*}}{100}\right)+\alpha_{4}$ RET

where $y^{*}$ is the average per capita income in the country measured in 1970 U. S. dollars and RET indicates the presence of an earnings test. The specification of linear and inverse terms in income parallels the earlier analysis.

In the notation of equations 1 and 2 , the total effect of the benefit replacement ratio is $\beta_{4}+\beta_{5} \alpha_{1}$. This can be calculated from the estimated structural parameters of equations 1 and 2 or it can be obtained directly by estimating the reduced form equation: 
(3)

$$
\begin{aligned}
\frac{S}{Y} & =\left(\beta_{0}+\beta_{5} \alpha_{0}\right)+\beta_{1} G+\beta_{2} \text { AGE }+\beta_{3} \text { DEP } \\
& +\left(\beta_{4}+\beta_{5} \alpha_{1}\right) \frac{B}{E}+\beta_{5} \alpha_{2}\left(\frac{100}{y^{*}}\right)+\beta_{5} \alpha_{3}\left(\frac{y^{*}}{100}\right) \\
& +\beta_{5} \alpha_{4} \text { RET } .
\end{aligned}
$$

Estimating the separate structural equations is asymptotically more efficient than estimating the reduced form, a property that may be of little significance with the current sample of only 12 observations. More relevant is the fact that a direct estimate of equation 3 would inevitably result in very wide confidence intervals because collinearity would raise the standard errors while the very small number of residual degrees of freedom would imply proportionately wider confidence intervals. Both types of estimates are discussed below. It is worth reiterating that while the composite reduced form coefficient $\beta_{4}+\beta_{5} \alpha_{1}$ measures the total effect of benefits on saving in the cample, it is the structural coefficient $\beta_{4}$ that tests the proposition of Pechman and Barro that, even with no change in retirement behavior, social security does not decrease private saving.

\section{The Data and Estimation Method}

The present analysis is based on data for the twelve countries for which the Social Security Administration estimated the "new retiree replacement ratio." To reduce the effects of cyclical fluctuations, the income, saving and benefit variables are averaged over the period 1969 through 1975. National income account data were obtained from National Accounts of OECD Countries, 1974 (OECD, 1976) and The 1976 Yearbook of National Account Statistics (United

\footnotetext{
IAustria, Canada, Denmark, France, Germany, Italy, Netherlands, Norway, Sweden, Switzerland, United Kingdom, and United States. Equations involving "life expectancy at age 65" exclude Austria for which data on this variable are not available.
} 
Nations, 1977a).1 Demographic data were obtained from the Demographic Yearbook, 1976 (United Nations, 1977b) and The 1977 Year Book of Labor Statistics

(Internationa1 Labor Organization, 1977).

More specifically, private saving $(S)$ is defined as total private saving and includes the savings of households, private institutions serving households, and corporations. 2 Unfortunately, the savings figures are all based on nominal accounting definitions; the result of this is to understate depreciation and overstate saving. Moreover, the extent of this overstatement will differ among the sample countries.

Private national income $(Y)$ is the difference between total national income and personal and corporate tax receipts net of tranfers. The growth rate (G) is the implicit constant annual percentage rate of growth of real private national income for the 15 year period from 1960 through 1975.

The variable AGE is the ratio of the number of retired persons age 65 and over to the number of persons between 20 and 65 years old. Similarly, DEP is defined as the ratio of the number of persons under 20 to the number between 20 and 65 . The labor force participation of the aged (LPAGED) is the percent of men aged 65 and older who are economically active.

The basic benefit replacement ratio $(B / E)$ is the "new retiree replacement ratio" (based on the benefits for a couple and the average earnings of a worker in manufacturing industry) as calculated by the Social Security Administration. The alternative "average replacement ratio" used in my earlier research is defined as the relative "benefits per aged person adjusted for the retirement

TStatistics for 1975 were obtained from the Data Resources, Inc. data bank containing these OECD and U.N. sources.

2 Including public as well as private corporations. 
test" (BPARA/y) and calculated by dividing the total amount of benefits received by the aged, survivors, and the disabled by the number of persons over age 65 or, in those countries with a retirement test, by the number of retired persons over age 65. The data on social security benefits is from International Labor Organization (1976).

The average per capita income in $1970 \mathrm{U}$. S. dollars ( $\mathrm{y}^{*}$ ) is calculated by converting domestic currency values to U. S. dollars at official exchange rates.

The retirement test indicator (RET) is a binary variable equal to one if the country imposes an earnings test as a condition of benefits for those beyond the normal retirement age for that country. The classification of tion (1978). In some specifications, we examined the implications of including the life expectancy of males at age 65 (LE65) and of a variable indicating the year in which the nation's social security system was started (START).

Because the savings function contains an endogenous variable as one of the regressors (LPAGED), ordinary least squares is not appropriate. Although two stage least squares has only asymptotic consistency, it still seems better to use this method even with the current small sample. The variables in equation 2 (plus LE65 and START) are included in the set of exogenous variables. Equation 2 can of course be estimated by ordinary least squares. The parameters of the reduced form equation can then be calculated from the estimated structural coefficients.

I have followed the procedure of Houthakker (1961, 1965), Modigliani (1970) and Feldstein (1977) by weighting each observation to reflect the size of the country's population. The estimation program adjusts the degrees 
of freedom, standard errors, etc. for these weights.l

Table 1 represents the values of the key variables for the 12 countries.

TABLE 1

SAVING RATES AND KEY DETERMINANTS

$\underline{S / Y} \quad \underline{G} \quad \underline{A G T} \quad \underline{D E P} \quad \underline{\text { LPAGED }} \quad \underline{\mathrm{B} / \mathrm{E}} \quad \underline{\mathrm{BPARA} / \mathrm{Y}}$

$\begin{array}{lrrrrrrr}\text { Austria } & 17.7 & 3.9 & 24.8 & 57.5 & 8.0 & 61.0 & 76.1 \\ \text { Canada } & 12.7 & 4.8 & 13.1 & 74.9 & 23.6 & 46.4 & 40.0 \\ \text { Denmark } & 6.5 & 2.7 & 26.9 & 52.8 & 21.9 & 43.2 & 61.7 \\ \text { France } & 15.7 & 4.9 & 24.0 & 55.8 & 10.6 & 60.6 & 79.5 \\ \text { Germany } & 16.4 & 3.4 & 24.0 & 51.7 & 11.0 & 50.6 & 78.8 \\ \text { Italy } & 19.9 & 4.7 & 18.2 & 55.1 & 13.4 & 66.0 & 76.6 \\ \text { Netherlands } & 19.4 & 4.3 & 17.8 & 66.1 & 11.6 & 52.2 & 100.9 \\ \text { Norway } & 9.2 & 3.9 & 20.4 & 58.4 & 25.7 & 52.4 & 85.2 \\ \text { Sweden } & 8.7 & 2.6 & 24.2 & 46.8 & 12.6 & 61.0 & 66.2 \\ \text { Switzerland } & 20.9 & 3.6 & 16.0 & 52.7 & 31.7 & 50.4 & 50.2 \\ \text { United Kingdom } & 8.7 & 1.6 & 20.9 & 55.6 & 19.3 & 34.4 & 46.3 \\ \text { United States } & 9.5 & 3.5 & 16.8 & 64.3 & 20.8 & 52.4 & 55.1\end{array}$

All proportions have been restated as percentages. See text for definitions, sources and sample period.

IWhen the principal equations were re-estimated without weights, none of the basic implications were altered. 


\section{The Parameter Estimates}

The estimated parameter values are generally consistent with the extended Iife cycle model described in section 1 and with the qualitative properties implied by the parameter estimates in Feldstein (1977). In particular, the coefficient of the social security variable in the saving function supports the conclusion that a high level of social security benefits depresses private saving when retirement behavior is fixed. Although the labor force participation equation confirms that high benefits also induce earlier retirement, the reduced form parameter implied by the structural coefficients indicates that, on balance, higher social security benefits reduce private saving.

Equation 4 presents the estimated parameter values of the savings function specified in equation 1 :

$$
\begin{aligned}
\frac{\mathrm{S}}{\mathrm{Y}}=0.92+5.24 \mathrm{G}-1.21 \text { AGE }-0.77 \text { DEP } & \\
\begin{array}{lll}
(1.33)(0.45) & (0.20) & \\
& & \\
-0.37(\mathrm{~B} / \mathrm{E})-0.54 \text { LPAGED } & \mathrm{R}^{2}=0.90 \\
(0.13) & \mathrm{SEE}=0.0182
\end{array} & \mathrm{~N}=12
\end{aligned}
$$

Note first that the five coefficients are all statistically significant ${ }^{l}$ and correspond to the qualitative predictions of the extended life cycle model.2 A high rate of growth of total real income $(G)$ raises the saving rate while more of the population over 65 (AGE) or under 20 (DEP) decreases the saving rate. These findings replicate the earlier Houthakker-Modigliani-Feldstein confirmation of the implications of the traditional life cycle theory. A higher fraction of older men who are working (LPAGED) implies less need for retirement assets and therefore a lower saving rate, a key feature of the IWith only 6 degrees of freedom, the 10 percent significance level (for a two tailed test) is 1.94 and the 5 percent significance level is 2.45 .

2 The coefficients are qualitatively similar to the estimates for 1954-60 presented in Feldstein (1977) but indicate that the sensitivity of saving to each of the variables has increased. This may however reflect the substitution of the new benefit replacement ratio for the previous average replacement ratio. 
extended life cycle model. 1 The coefficient of -0.54 (with a standard error of 0.27 implies quite substantial sensitivity of saving to this measure of retirement behavior; a one standard deviation increase in the retirement ratio (i.e., a move of LPAGED by 0.049 ) reduces the saving rate by 0.02 or half of one standard deviation of the saving rate in the 12 country sample. 2

The coefficient of the social security benefit variable $(B / E)$ is -0.37 with a standard error of 0.15 . This is clearly incompatible with the proposition that social security is ignored by savers or that it induces greater savings for retirement. It is also incompatible with the view that a shift in private intergenerational transfers negates any other effect of social security on private saving. The magnitude of the coefficient implies that a 10 percentage point increase in the benefit replacement ratio would, ceteris paribus, lower the saving rate by 3.7 percentage points or approximately one standard deviation.1

A number of other secondary variables that might cause intercountry differences in saving. were tried as additions to the variables in equation 4 but their coefficients were always insignificant. For example, when the variable measuring life expectancy at age 65 (LE65) was added to equation 4 its coefficient was positive as expected but completely insignificant (a t-statistic of less than 0.5$)$. The coefficients of the other variables remained essentially unchanged but their standard errors increased as a result of the collinearity among the regressors. The other variables that were tried include the retirement test (RET), the starting date (START) and the level of income $\left(100 / \mathrm{y}^{*}\right)$. It might of course be argued that when the saving rate is low for other reasons individuals cannot "afford" to retire, implying that the direction of causation is reversed or at least simultaneous. I have not explored that possibility.

2For the 12 countries, S/Y has a mean of 0.12 and a standard deviation of 0.04 . 3 According to the calculations by the Social Security Administration, the U.S. new retiree replacement ratio rose 13 percentage points between 1969 and 1975 . (Haanes-01sen, 1978, p.4) 
Equations with these additional variables are presented in appendix table A-l.

Equation 4 and the related equations with additional variables were reestimated using the "average replacement ratio" calulated from social security type benefit payments (BPARA/y). The overall fit of the equation was substantially worse; the standard error of the estimate rose from 0.0135 in equation 4 to 0.0273 when $B / E$ was replace by BPARA/y. All of the standard errors became larger and no variable had a coefficient with a t-statistic as large as 2.0. The replacement rate variable itself was completely insignificant. The addition of other explanatory variables did not change the general character of this result and left the standard error of the estimate substantially larger than in equation 4. It seems reasonable to conclude that saving decisions are being influenced more by the benefits being paid to new retirees than by the average benefit being paid to retirees of all ages. ${ }^{l}$ It is not clear why the average benefit variable no longer appears to influence saving in the way that it did in the earlier sample. The difference in coefficients may reflect an increased discrepancy between average benefits and new retiree benefits, greater measurement error is the calculation of average benefits, or the possibility that either the current or the previous estimates were merely the result of chance. Equation 5 presents the estimated coefficients of the basic labor force participation function:

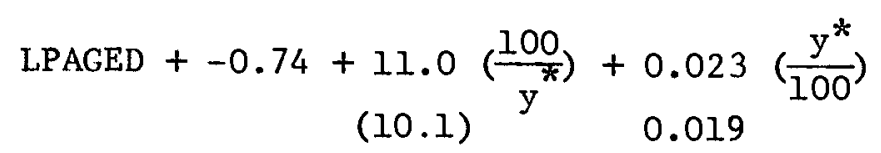

$$
\begin{gathered}
-0.29\left(\frac{B}{E}\right)-3.0 \operatorname{RET} \\
(0.13)
\end{gathered}
$$

$$
\begin{aligned}
\mathrm{R}^{2} & =0.71 \\
\mathrm{SEE} & =0.024 \\
\mathrm{~N} & =12
\end{aligned}
$$

I Individual households and pension planners may also be basing their saving decisions on more accurate knowledge of future benefit rules which are better approximated by $\mathrm{B} / \mathrm{E}$ than by BPARA/y. Alternatively, the poor statistical performance of BPARA/y may only reflect measurement problems with this variable. 
The coefficient of primary interest, that of the benefit replacement ratio, confirms that higher benefits do induce earlier retirement. An increase in the benefit ratio of 10 percentage points reduces the labor force participation by 2.9 percentage points; for comparison, the labor force participation rates in the sample had a mean of 17.5 percent and a standard deviation of 4.9 percent. Although the coefficients of the two income variables are subject to substantial uncertainty, it is interesting to note that the combined effect of the two coefficients is similar to the behavior implied by the coefficients for 1954 to 1960 in Feldstein (1977): for the lower income countries, the income effect dominates the substitution effect and increasing income lowers LPAGED while for higher income countries the opposite is true. Because the mean real income is much higher in the current sample than it was in the 1950's, the substitution effect now dominates at the mean income.

The coefficient of the retirement test variable (RET) has the correct sign but is not significantly different from zero, a result that characterized the earlier study as well. This may reflect the inadequacy of this binary variable as a measure of the complex earnings tests, the oversimplicity of the linear specification, or even the unlikely possibility that it is the availability of benefits rather than the earnings test that is the crucial determinant of retirment behavior.

Equation 5 was also estimated with the addition of life expectancy at age 65 (LE65) and the maturity of the social security program (START) but neither of these variables was significant. Substituting the average benefit replacement ratio $(B P A R A / y)$ for the new retiree replacement ratio $(B / E)$ leaves the estimated effect of social security on retirement essentially unchanged but makes all of the other variables completely insignificant (i.e., their coefficients have TThe coefficient falls from -0.29 to -0.23 but BPARA/Y is larger on average than $\mathrm{B} / \mathrm{E}$. 
t-statistics of less than 0.5$) .1$

The parameters of the reduced form savings function (equation 3 ) can in principle be estimated directly by ordinary least squares. Unfortunately, estimating the 8 parameters with only 12 observations leaves all of the coefficients with relatively large standard errors (no coefficient is as large as 1.5 times its standard error). For example, the coefficient of $B / E$ is -0.16 with a standard error of 0.27 . There is too little information in the sample to obtain useful estimates of reduced form parameters in this way.

Alternatively, the estimated coefficients of equations 4 and 5 can be combined to calculate the reduced form parameters. The resulting equation is:

$$
\frac{\mathrm{S}}{\mathrm{Y}}=1.32+5.24 \mathrm{G}-1.21 \mathrm{AGE}-0.77 \mathrm{DEP}
$$

$$
-0.21\left(\frac{\mathrm{B}}{\mathrm{E}}\right)-5.9\left(\frac{100}{\mathrm{y}^{*}}\right)-0.012\left(\frac{\mathrm{y}^{*}}{100}\right)+1.6 \operatorname{RET}
$$

The net effect of higher social security benefits is thus to reduce the saving rate; the wealth replacement effect outweighs the induced retirement effect. An approximate standard error of $\beta_{4}+\beta_{5} \alpha_{1}=-0.21$ can be obtained easily on the assumption that the parameter estimates of equation 4 and 5 are uncorrelated. The error variance of this nonlinear function of the parameter estimates is then approximated in the usual way by the expected value of the square of the first order terms in the expansion of this function. The standard error estimated in this way is 0.16 , indicating that the probability is less than 0.15 that

It is of course possible that BPARA/Y is the relevant variable for determining retirement since that behavior depends on the benefits available to the current population over age 65 while $\mathrm{B} / \mathrm{E}$ is relevant for the more forward-looking saving decisions among the population of working age. 
the estimated effect of social security benefits of 0.21 could be obtained by chance if the true value were zero or negative.l.

\section{Conclusion}

The results of this study should be evaluated in conjunction with all of the other evidence on private saving and social security. By itself, the present sample is too small and the problems of measurement are too great to warrant reliance on the specific parameter values. But the new estimates do support and reinforce the conclusions of earlier studies that indicate the appropriateness of the extended life cycle model of saving behavior in general and the negative impact of social security benefits on private saving in particular.

In an earlier stage of the analysis, the sample was restricted to the eleven countries (excluding Austria) for which data on LE65 were available. For this sample, the total effect of social security is estimated to be -0.33 (instead of -0.21 ) and its approximate standard error is 0.11 . 
TABLE A-1

ALTERNATE SAVING RATE EQUATIONS

\begin{tabular}{|c|c|c|c|c|c|c|c|c|c|c|c|}
\hline Equation & Constant & $\underline{G}$ & $\underline{A G E}$ & DED & $\underline{B} / E$ & LPAGED & LEGS & $100 / y^{*}$ & RET & START & $\underline{S E E}$ \\
\hline$A-1$ & 0.92 & $\begin{array}{c}5.24 \\
(1.33)\end{array}$ & $\begin{array}{l}-1.21 \\
(0.45)\end{array}$ & $\begin{array}{l}-0.77 \\
(0.20)\end{array}$ & $\begin{array}{c}-0.37 \\
(0.13)\end{array}$ & $\begin{array}{l}-0.54 \\
(0.27)\end{array}$ & & & & & \\
\hline$A-2$ & 1.02 & $\begin{array}{c}6.07 \\
(1.06)\end{array}$ & $\begin{array}{l}-1.35 \\
(0.33)\end{array}$ & $\begin{array}{l}-0.92 \\
(0.16)\end{array}$ & $\begin{array}{c}-0.45 \\
(0.12)\end{array}$ & $\begin{array}{l}-0.42 \\
(0.17)\end{array}$ & & & & & 0.0135 \\
\hline$A-3$ & 1.02 & $\begin{array}{c}6.37 \\
(1.50)\end{array}$ & $\begin{array}{l}-1.44 \\
(0.46)\end{array}$ & $\begin{array}{l}-1.01 \\
(0.33)\end{array}$ & $\begin{array}{l}-0.53 \\
(0.30)\end{array}$ & $\begin{array}{l}-0.49 \\
(0.29)\end{array}$ & $\begin{array}{c}0.85 \\
(2.75)\end{array}$ & & & & 0.0144 \\
\hline$A-4$ & $\begin{array}{c}1.21 \\
(3.34)\end{array}$ & $\begin{array}{c}6.97 \\
(0.61)\end{array}$ & $\begin{array}{c}-1.75 \\
(0.41)\end{array}$ & $\begin{array}{l}-1.21 \\
(0.41)\end{array}$ & $\begin{array}{l}-0.66 \\
(0.34)\end{array}$ & $\begin{array}{l}-0.62 \\
(0.33)\end{array}$ & $\begin{array}{c}1.43 \\
(0.28)\end{array}$ & $\begin{array}{l}-0.41 \\
(0.51)\end{array}$ & & & 0.0142 \\
\hline$A-5$ & 1.05 & $\begin{array}{c}4.84 \\
(2.81)\end{array}$ & $\begin{array}{l}-1.44 \\
(0.52)\end{array}$ & $\begin{array}{c}-0.85 \\
(0.43)\end{array}$ & $\begin{array}{l}-0.30 \\
(0.46)\end{array}$ & $\begin{array}{l}-0.37 \\
(0.37)\end{array}$ & $\begin{array}{l}-0.62 \\
(3.88)\end{array}$ & & $\begin{array}{l}-1.64 \\
(2.41)\end{array}$ & & 0.0164 \\
\hline$A-6$ & 2.21 & $\begin{array}{c}5.64 \\
(2.34)\end{array}$ & $\begin{array}{l}-1.41 \\
(0.56)\end{array}$ & $\begin{array}{l}-0.89 \\
(0.47)\end{array}$ & $\begin{array}{l}-0.37 \\
(0.47)\end{array}$ & $\begin{array}{l}-0.31 \\
(0.51)\end{array}$ & $\begin{array}{c}0.51 \\
(0.34)\end{array}$ & & & $\begin{array}{l}-0.07 \\
(0.15)\end{array}$ & 0.0174 \\
\hline
\end{tabular}

The dependent variable in each equation is $\mathrm{S} / \mathrm{Y}$. Equations are estimated by weighted TSLS for the sample described in the text. Standard errors are shown in parentheses. Equation A-1 repeats equation 4 of the text. Equations A-2 through A-6 are based on only 11 observations. 
$\underline{\text { References }}$

Barro, R. (1978), "The Impact of Social Security on Private Savings," The American Enterprise Institute Studies, \#199.

Barro, Robert J. and MacDonald, Glenn M., "Social Security and Consumer Spending in an International Cross Section," Journal of Public Economics, forthcoming. Boskin, Michael J. (1977), "Social Security and Retirement Decisions," Economic Inquiry, (January), vol. 15, no. 1 .

Feldstein, M. (1977), "Social Security and Private Savings: International

Evidence in an Extended Life-Cycle Model," in The Economics of Public Services, an International Economic Association Conference Volume, M. Feldstein and $\mathrm{R}$. Inman (eds.).

Feldstein, Martin (1978), "Do Private Pensions Increase National Saving?" Journal of Public Economics (December), vol. 10, no. 3 . Feldstein, Martin (1979), "The Effect of Social Security on Saving," National Bureau of Economic Research Working Paper No. 334. Haanes-Olsen, L. (1978), "Earnings-Replacement Rate of Old-Age Benefits, 1965-75, Selected Countries," Social Security Bullentin, (January), Vol . 4l, No. 1 .

Harrod, R. (1948), Towards a Dynamic Economic. London: Macmillan. Houthakker, H. (1965), "An International Comparison of Personal Saving," Bulletin of the International Statistical Institute, \#38. Houthakker, H. (1965), "On Some Determinants of Saving in Developed and Underdeveloped Countries," in Problems of Economic Development, E. Robinson (ed.). London: Macmillan, ch. 10 . 


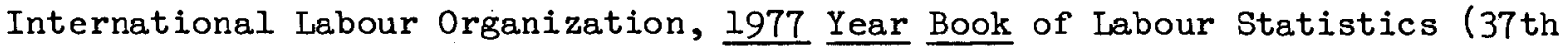
issue). Geneva: International Labour Organization, 1977. Katona, G. (1965), "Private Pensions and Individual Saving," Survey Research Center, Institute for Social Research, University of Michigan. Modigliani, F. (1966), "The Life Cycle Hypothesis of Saving, the Demand for Wealth and the Supply of Capital," Social Research (Summer), Vol. 33, no. 2. Modigliani, F. (1970), "The Life Cycle Hypothesis of Saving and Intercountry Differences in the Saving Ratio," in W. A. Eltis et al. (ed.), Induction Growth and Trade, Essays in Honor of Sir Roy Harrod, Oxford. Modigliani, F. and Brumberg, R. (1954), "Utility Analysis and the Consumption Function: An Interpretation of Cross-Section Data," in $\mathrm{K}$. Kurihara (ed.), Post Keynesian Economics, New Brunswick. OECD, National Accounts of OECD Countries, Paris: OECD, 1976. Pechman, J., Aaron, H. and Taussig, M. (1968), Social Security: Perspectives for Reform. Washington: The Brookings Institution. United Nations Department of Economic and Social Affairs, Statistical Office, 1976 Yearbook of National Account Statistics. New York: United Nations, 1977a.

United Nations Department of Economic and Social Affairs, Statistical Office, Demographic Yearbook 1976 (28th issue). New York: United Nations, $1977 \mathrm{~b}$.

United States Department of Health, Education, and Welfare, Social Security Administration, Office of Research and Statistics, Social Security Programs Throughout the World, 1977. Washington, D.C.: United States Government Printing Office, 1978). 